Check for updates

Cite this: RSC Adv., 2017, 7, 52475

\title{
Corrosion mechanism for local enrichment of acids and copper ions in copper-insulating paper contacts leading to the acceleration of copper sulfide formation induced by dibenzyl disulfide
}

\begin{abstract}
Sihang Gao, (D) a Lijun Yang, ${ }^{\star a}$ Bangfei Deng ${ }^{\mathrm{b}}$ and Jiang Zhang ${ }^{\mathrm{a}}$
Numerous failures of high-voltage transformers occur because of sulfur corrosion in oil-impregnated paper insulation containing dibenzyl disulfide (DBDS). This study determines the effects of DBDS, the copperinsulating paper contact, the insulating paper and the atmosphere on copper sulfide formation. Accelerated thermal aging experiments were conducted for mineral oil that contained DBDS and insulation windings under atmospheric (nitrogen/air) conditions. The corrosive sulfur deposits were quantified using SEM/EDX, ICP-AES and precipitation methods. Oil acidity was measured and analyzed. The study proposes a corrosion mechanism for local enrichment of acids and copper ions in copperinsulating paper contacts leading to the acceleration of sulfur corrosion.
\end{abstract}

Received 30th September 2017 Accepted 20th October 2017

DOI: 10.1039/c7ra10816h

rsc.li/rsc-advances

corporation suggested that the reaction of copper and DBDS can

\section{Introduction}

Oil-immersed power transformers are important in power systems. The main insulation system of transformers consists of insulating oil, oil-impregnated insulating pressboard, and insulation windings. Copper is a preferred conductive material due to its stable physicochemical properties and low electrical resistivity. Thus, it is extensively used in oil-immersed power transformers. Insulation windings comprise copper strips wrapped with insulating paper and immersed in transformer oil to provide insulation for current and voltage transmissions. ${ }^{1}$ However, copper corrosion still exists in electrical power equipment; thus, copper is vulnerable to corrosion-related failures. $^{3}$ Numerous studies have illustrated that dibenzyl disulfide (DBDS) is one of the main corrosive sulfur compounds in transformer oil; it causes copper sulfide formation on insulation windings. Copper sulfide is a gray-black solid with high conductivity, which weakens the dielectric strength of oilimmersed paper and reduces insulation resistance. ${ }^{\mathbf{4} 6}$ This failure in transformers has attracted considerable attention. Thus, copper sulfur corrosion in oil-paper insulation has been investigated in several studies.

Recent studies have been performed to explore the corrosion mechanism of copper sulfide formation, influencing factors, and remedial procedures of corrosion in oil-immersed insulation. The Mitsubishi Company in Japan proposed a possible corrosion mechanism for copper sulfide formation. ${ }^{7}$ This

${ }^{a}$ State Key Laboratory of Power Transmission Equipment and System Security and New Technology, Chongqing University, Chongqing, 400044, China

${ }^{b}$ State Grid Chongqing Electric Power Research Institute, Chongqing, 400015, China form DBDS-Cu compound that diffuses through insulating oil. DBDS-Cu compound partially dissolves in oil and adsorbs onto insulation windings. DBDS-Cu compounds then decompose into copper sulfide, dibenzyl sulfide (DBS), and bibenzyl (BiBZ) on insulation windings. Another corrosion mechanism for copper sulfide formation was proposed by Facciotti et al. ${ }^{8}$ They studied the influence of DBDS, oxygen, time, and $\mathrm{Cu}$-paper contact upon copper sulfide formation, proposed a contactbased mechanism to explain copper sulfide contamination of insulating paper, and investigated the detachment and mobilization of copper sulfide deposits from the copper surface into insulating paper. Oxygen was observed to interfere with surface interaction between copper sulfide and copper, which causes metal displacement. ABB Company in the United States stated that mercaptan (R-SH) is a major corrosive sulfur compound and that it can react with copper under aerobic condition to generate copper sulfide. ${ }^{9}$ Previous investigations have also revealed that copper sulfide formation is influenced by various factors, such as temperature, concentration of corrosive sulfur compound (i.e., DBDS), oxygen, and 2, 6-di-tert-butyl-p-cresol (DBPC). ${ }^{\mathbf{1 0 - 1 5}}$ Some studies have shown that the addition of metal passivators can suppress corrosion of insulation windings to a certain extent and that the replacement of insulating oil fails to solve winding corrosion. ${ }^{\mathbf{1 6}-18}$ The findings from these previous studies are illustrated and presented on CIGRE WG A240 , which is used worldwide. ${ }^{19}$

In the presence of insulation windings, copper sulfide formation by insulating oils is considered a potential threat to oil-immersed transformers. Thus, several test methods have been adopted to detect corrosive and potentially corrosive sulfur 
compounds in used and unused insulating oils. The main test methods are as follows: DIN 51353, ${ }^{20}$ ASTM D 1275A, ASTM D $1275 \mathrm{~B},{ }^{21}$ and IEC $62535 .^{22}$ However, these test methods differ to a certain extent. For DIN 51353, a silver conductor is immersed in oil and heated for $18 \mathrm{~h}$ at $100{ }^{\circ} \mathrm{C}$ in a sealed glass headspace vial. For ASTM D 1275A and ASTM D 1275B, a copper conductor is immersed in oil and heated for $19 \mathrm{~h}$ at $140{ }^{\circ} \mathrm{C}$ and for $48 \mathrm{~h}$ at $150{ }^{\circ} \mathrm{C}$, respectively, in a sealed glass headspace vial filled with nitrogen. However, these detection methods cannot identify oils containing potentially corrosive sulfur. ${ }^{22}$ Thus, International Electrotechnical Commission (IEC) prepared international standards for detecting potentially corrosive sulfur compounds in mineral insulating oils. Wrapped conductors immersed in oil under air condition are suitable for used and unused mineral oils. For IEC 62535, a piece of copper conductor wrapped with Kraft paper is immersed in oil and heated for $72 \mathrm{~h}$ at $150{ }^{\circ} \mathrm{C}$ in a sealed glass headspace vial filled with air. IEC 62535 is currently recognized as the most effective test method for detecting oils with potentially corrosive sulfur compounds. Copper conductors wrapped with Kraft paper and reaction conditions (under air condition) represent the main differences between IEC 62535 detection and other test methods.

Moreover, a large number of field samples have revealed that copper sulfide mainly deposits on the surface of copper strips and inner insulating paper. Based on the contact-based mechanism between copper strip and insulating paper, ${ }^{8}$ insulating papers may play an important role in copper sulfide deposition on insulation windings. Degradation of oil-paper insulation generates aging polar products, such as acidic substances and copper ions. ${ }^{23,24}$ Therefore, the role of insulating papers in copper sulfide deposition on insulation windings warrants further investigation.

The present study further explores the effect of DBDS, copper-insulating paper contact, insulating paper, and atmosphere on copper sulfide formation. A series of thermal aging experiments were conducted under different conditions. Macro and micro studies on insulation windings after aging experiments were described using scanning electron microscopy (SEM)/energy-dispersive X-ray spectroscopy (EDX). Inductively coupled plasma atomic emission spectrometry (ICP-AES) and precipitation method were used to quantify the corrosion degree of insulation windings; the acidity of insulating oil was also measured and analyzed. Combined with previous studies about corrosion mechanisms, the present study investigated the copper sulfide contamination of insulation windings.

\section{Experimental}

\subsection{Sample preparation}

Analytical-grade reagents (AR) were used. DBDS (AR, 99\%) was purchased from China Huaxia Chemical Reagent Co., Ltd. The insulating oil used was Karamay \#25 mineral oil provided by China Chongqing ChuanRun Petroleum Chemical Co., Ltd. Karamay mineral oil features favorable electrical properties and oxidation stability, and antioxidant (2,6-di-tert-butyl-4methylphenol) mass concentration of $0.3 \%$ and maximum total sulfur content of $0.05 \%$. This oil presents no detectable

DBDS and metal passivator additives; it is also non-corrosive according to standard corrosion test IEC $62535 .{ }^{22}$ Table 1 lists the oil parameters according to specifications of ASTM D34872000 (II). Insulation windings were provided by China Chongqing ABB Transformer Co., Ltd. Copper strips were generated from an electrolytic tough pitch copper measuring $12 \mathrm{~mm}$ in width, $2 \mathrm{~mm}$ in thickness, and $70 \mathrm{~mm}$ in length. Each conductor was wrapped with four layers of $0.08 \mathrm{~mm}$-thick insulating paper, which measured $20 \mathrm{~mm} \times 100 \mathrm{~mm} \times 0.08$ $\mathrm{mm}$. In the current experiment, insulation windings were divided into three categories (Table 2). The entire copper strip wrapped with insulating paper, the half of the copper strip wrapped with insulating paper, and the bare copper strip are defined as Windings I, II, and III, respectively.

\subsection{Experimental setup and procedure}

A series of thermal aging experiments were conducted under different conditions to explore the comprehensive effects of DBDS, copper-insulating paper contact, and atmosphere on copper sulfide formation. Mineral oil with $500 \mathrm{mg} \mathrm{kg}^{-1}$ DBDS and three types of insulation windings were aged at $130{ }^{\circ} \mathrm{C}$ under nitrogen or air condition. Table 3 shows the experimental conditions.

Oil-paper insulation was gradually oxidized to generate a series of oxidation products. During this operation, acidic substances (e.g., oleic acid, formic acid, naphthenic acid, hydroxyl acid, and other acids) became deleterious. Various acids and acidic substances increase oil conductivity and accelerate the aging of solid fibers. ${ }^{27}$ Thus, the acidity of insulating oil directly reflects the aging degree of oils. ${ }^{2}$ The presence of more acidic substances in oil insulation usually results in higher oil acidity. Acidic substances include high and low molecular-weight acids and they are generated by the aging of oil-paper insulation in oil-immersed transformers. A clear synergy of the aging rates of solid fibers between moisture and low molecular-weight acids was found. No effect for high molecular-weight acids was observed. The partitioning of acids in oil-cellulose insulation is governed by molecular weight, that is, the lower the molecular weight the more the paper adsorbs, and higher the molecular weight the less the paper adsorbs; thus, most high molecular-weight acids mainly exist in insulating oil. ${ }^{28-30}$ Therefore, high molecular-weight acids easily dissolve in insulating oils. Low molecular-weight acids are more likely to transfer to insulating papers. Thus, specific amounts of

Table 1 Typical parameters of Karamay \#25 mineral oil used in the experiment

Property

Density, $\mathrm{kg} \mathrm{m}^{-3}$

Kinematic viscosity $\left(40{ }^{\circ} \mathrm{C}\right), \mathrm{mm}^{2} \mathrm{~s}^{-1}$

Pour point, ${ }^{\circ} \mathrm{C}$

Flash point, ${ }^{\circ} \mathrm{C}$

Acidity, $\mathrm{mg} \mathrm{KOH} \mathrm{g}^{-1}$

Breakdown voltage ( $2.5 \mathrm{~mm}$ gap electrode, $\mathrm{kV}$ )

Antioxidant content (DBPC), \%

Corrosive sulfur

Mineral oil
884.6
9.652
$<-24$
143
$<0.01$
38
0.3
Non-corrosive

884.6

$<-24$

Non-corrosive 
Table 2 Classification of insulation windings used in the experiment

\begin{tabular}{ll}
\hline Winding category & Description \\
\hline Winding I & $\begin{array}{l}\text { Copper strip is wrapped with insulating } \\
\text { paper }\end{array}$ \\
Winding II & $\begin{array}{l}\text { Half of the copper strip is wrapped with } \\
\text { insulating paper, and the other half is bare } \\
\text { Bare copper only }\end{array}$
\end{tabular}

oleic acid (AR, 95\%), which simulated high molecular-weight acids, and formic acid (AR, 95\%), which simulated low molecular-weight acids, were selected to simulate acids generated during the aging of oil-paper insulation. The AR of formic and oleic acids was graded 95.0\%. Each type of winding involved seven experimental sets, including no acid, oleic acid (0.05, $\left.0.1 \mathrm{mg} \mathrm{KOH} \mathrm{g}^{-1}\right)$, formic acid $\left(0.05,0.1 \mathrm{mg} \mathrm{KOH} \mathrm{g}^{-1}\right)$, and a combination of oleic and formic acids (0.025/0.025, 0.05/ $\left.0.05 \mathrm{mg} \mathrm{KOH} \mathrm{g}{ }^{-1}\right)$. Mineral oil with $500 \mathrm{mg} \mathrm{kg}^{-1}$ DBDS and three types of windings were aged at $130{ }^{\circ} \mathrm{C}$ with and without formic or oleic acids under nitrogen condition. The experimental conditions are shown in Table 4.

Aging experiment was conducted as follows.

Step 1. Insulating oil with $500 \mathrm{mg} \mathrm{kg}^{-1}$ DBDS and windings were placed in a vacuum chamber at $90{ }^{\circ} \mathrm{C} / 50 \mathrm{~Pa}$ for $48 \mathrm{~h}$. Afterward, windings were placed in oil at $40{ }^{\circ} \mathrm{C} / 50 \mathrm{~Pa}$ and immersed for $48 \mathrm{~h}$.

Step 2. The three types of winding and $100 \mathrm{~mL}$ oil with and without acids were placed in glass vessels, which were then placed in stainless tanks, filled with nitrogen (air), and sealed (opened).

Step 3. Stainless tanks were placed in an aging chamber at $130{ }^{\circ} \mathrm{C}$, and insulation windings and insulating oils were retrieved from the stainless tank at intervals during aging.

Table 3 Experimental conditions for the study of the effects of DBDS, copper-insulating paper contact, and atmosphere on copper sulfide formation

\begin{tabular}{lll}
\hline $\begin{array}{l}\text { Winding } \\
\text { category }\end{array}$ & Insulating oil & Thermal aging condition \\
\hline $\begin{array}{ll}\text { Winding I } \\
\text { Winding II }\end{array}$ & $\begin{array}{l}100 \mathrm{~mL} \mathrm{oil} \mathrm{with} \\
\text { Winding III }\end{array}$ & $\begin{array}{l}\text { At } 130{ }^{\circ} \mathrm{C} \text { under nitrogen } \\
\text { or air environment }\end{array}$ \\
\end{tabular}

For Winding II, half-bare copper strip was specified as area I, and the other half of the copper strip wrapped with insulating paper was designated as area II, as shown in Fig. 1.

\subsection{Characterization}

Four methods were applied to evaluate the corrosion degree of insulation windings qualitatively and quantitatively. The first method used the tarnish level chart ASTM D 130 to compare the contamination degrees of the copper strips. ${ }^{31}$ (Fig. 2).

The second method employed SEM and EDX produced by TESCAN Company to analyze microscopic morphology and composition elements on the surface of insulation windings. The third method used ICP-AES to measure the amount of copper deposited on the insulating paper and the copper ions dissolved in oil. The test details and process of ICP-AES are presented below.

Step 1. The calibration curve for copper content should be determined. The copper content for a standard solution was 500 ppm. Different copper concentration solutions were configured through dilution $(0,0.1,0.2,0.4,0.6,0.8$, and $1 \mathrm{ppm})$ and then analyzed by ICP-AES. The calibration curve could finally be determined. R2 reached at least 99.9\%, as shown in Fig. 3.

Step 2. After the aging experiment, insulating paper/oil was placed into a crucible equipped with a lid, carbonized by an electric furnace, and then burned to ashes in a muffle furnace. The ashes were cooled to room temperature and dissolved in $4 \%$ nitric acid for $1 \mathrm{~h}$.

Step 3. The solution was tested by using ICP-AES, and copper content was determined by comparing its peak intensity to the

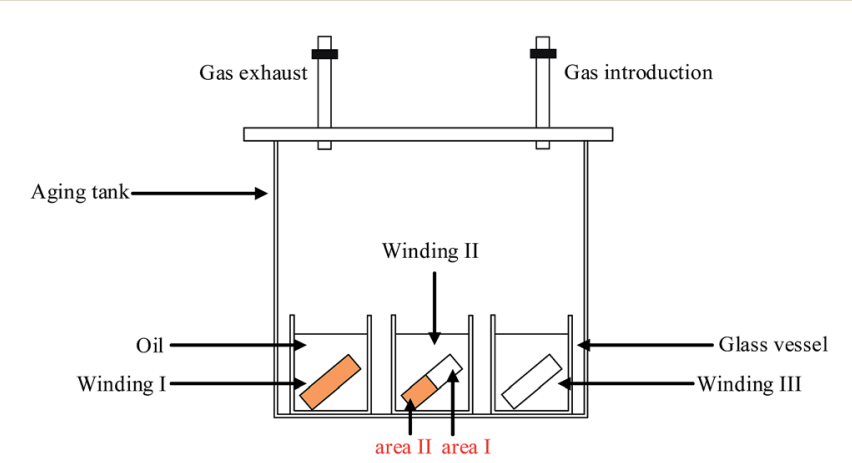

Fig. 1 Configuration of experimental setup and winding samples used in the experiment.

Table 4 Experimental conditions for the study of the effects of acidic substances on copper sulfide formation

\begin{tabular}{|c|c|c|c|c|}
\hline Winding category & Insulating oil & Acid category & $\begin{array}{l}\text { Serial number with different } \\
\text { samples (acid, } \mathrm{mg} \mathrm{KOH} \mathrm{g}^{-1} \text { ) }\end{array}$ & Thermal aging condition \\
\hline
\end{tabular}




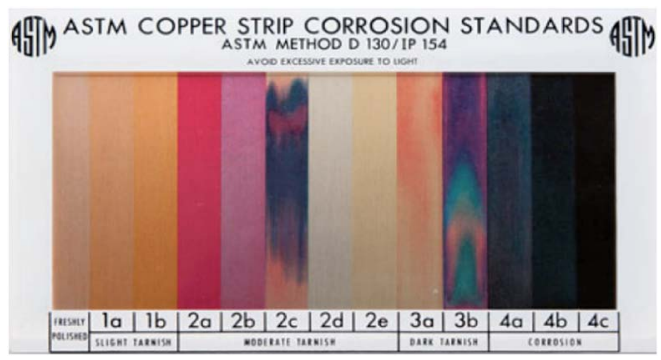

Fig. 2 Color chart used in ASTM D 130 corrosive test.

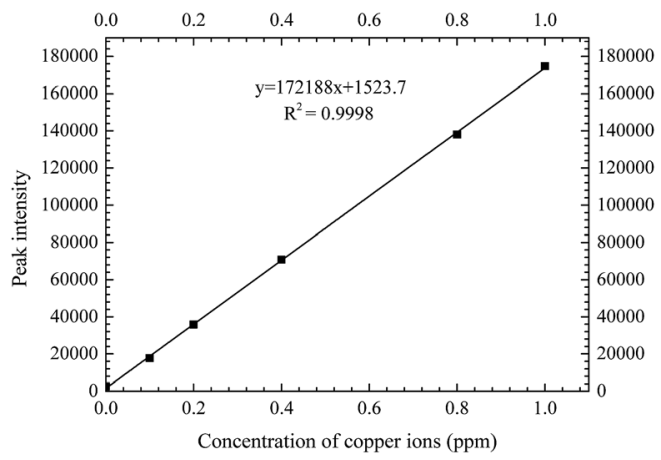

Fig. 3 Calibration curve of copper ion concentration.

peak intensity of the standard solution. Each sample was tested four times via ICP-AES, and an error bar was added to the results.

The last method involved precipitation method, which was used to measure the amount of sulfur on the copper strips. The test is described as follows. Barium chloride solutions and nitric acid were reacted with copper sulfide. Precipitate was measured using a precipitation method, and the amount of sulfur deposited on the copper strip was then calculated..$^{15}$ First, a copper strip was placed in a $1: 1(\mathrm{v} / \mathrm{v})$ nitric acid solution. Second, additional amount of barium chloride solution was added to nitric acid solution until precipitation ceased. Third, precipitate was filtered, transferred to crucibles, and then placed in a furnace for drying. Fourth, the crucible containing barium sulfate was removed from the furnace, cooled to room temperature, and weighed using an electronic balance.

Chemical reaction principles are described as follows:

$$
16 \mathrm{HNO}_{3}+3 \mathrm{Cu}_{2} \mathrm{~S} \rightarrow 3 \mathrm{Cu}\left(\mathrm{NO}_{3}\right)_{2}+3 \mathrm{CuSO}_{4}+10 \mathrm{NO}+8 \mathrm{H}_{2} \mathrm{O}
$$

$$
\mathrm{CuSO}_{4}+\mathrm{BaCl}_{2} \rightarrow \mathrm{BaSO}_{4}+\mathrm{CuCl}_{2}
$$

Contents are calculated as follows:

$$
W_{3}=\left(\frac{W_{1}-W_{2}}{233.39}\right) \times 32
$$

where $W_{1}$ corresponds to the weight of the crucible that contains the barium sulfate solution after drying, $W_{2}$ refers to the weight of the crucible, and $W_{3}$ represents the mass of sulfur in the copper sulfide.
In general, copper sulfide generated in the corrosion can be deposited on the copper strip and insulating paper, the amount of copper sulfide deposited on the copper strip is represented by the content of sulfur and the amount of copper sulfide deposited on the insulating paper is embodied by the content of copper.

The acidity of insulating oils was measured by potentiometric titration according to IEC62021. ${ }^{27}$

\section{Results}

\subsection{Surface morphologies of insulation windings}

Table 5 shows the surface morphologies of insulation windings aged at $130{ }^{\circ} \mathrm{C}$ under nitrogen atmosphere. For Winding I, corrosion was indicated by visible gray-black deposits on copper strips and inner insulating paper. The corrosion degree of copper strips and inner insulating paper intensify with the increase in aging time, increasing from $2 \mathrm{~b}$ to $3 \mathrm{~b}$ according to the tarnish level chart ASTM D 130. However, few deposits accumulated on the outer insulation paper. For Winding II, some deposits were observed on area II of the copper strips and inner insulating paper, and corrosion degree of increased from $2 \mathrm{~b}$ to $3 \mathrm{~b}$. However, no deposit was found on area I of the copper strips during aging. For Winding III, no deposit was observed on the copper strips during aging. These findings indicated that insulating paper may play a vital role in the formation of corrosive deposits. The bare copper strip cannot be corroded under nitrogen condition even when under high DBDS concentration in insulating oil.

Table 6 provides the surface morphologies of insulation windings aged at $130{ }^{\circ} \mathrm{C}$ under air condition. For Winding I, numerous corrosive deposits accumulated on the copper strips and inner insulating paper, and corrosion was more serious than that under nitrogen condition. The corrosion degree of the copper strip increased from $3 \mathrm{~b}$ to $4 \mathrm{~b}$ with aging time, and almost no deposit accumulated on the outer insulating paper. For Winding II, a number of corrosive deposits were observed on area II of the copper strips and inner insulating paper, which indicated more serious corrosion than that under nitrogen condition. The corrosion degree of area II of the copper strip also increased from $3 \mathrm{~b}$ to $4 \mathrm{~b}$ with aging time. However, no deposit was observed on area I of the copper strips until the late phase of aging, and the corrosion degree at day 28 of aging reached $4 \mathrm{~b}$. For Winding III, a significant number of corrosive deposits were precipitated on the copper strips under air condition, indicating apparent corrosion of copper strips under such condition. With the increase in aging time, the corrosion degree of the copper strip increased from $3 \mathrm{~b}$ to $4 \mathrm{c}$. The corrosive deposits on the insulation windings under air condition were darker than those under nitrogen condition. Moreover, the amount of corrosive deposits on insulation windings under air condition was considerably higher than that under nitrogen condition. Therefore, based on the preliminarily results, the existence of oxygen-accelerated corrosion resulted in a large amount of corrosive deposits on insulation windings.

Table 7 shows the surface morphologies of the insulation windings after the acid experiment at $130{ }^{\circ} \mathrm{C}$ under nitrogen 
Table 5 Surface morphologies of the three types of windings, including copper strip and inner insulating paper under nitrogen condition

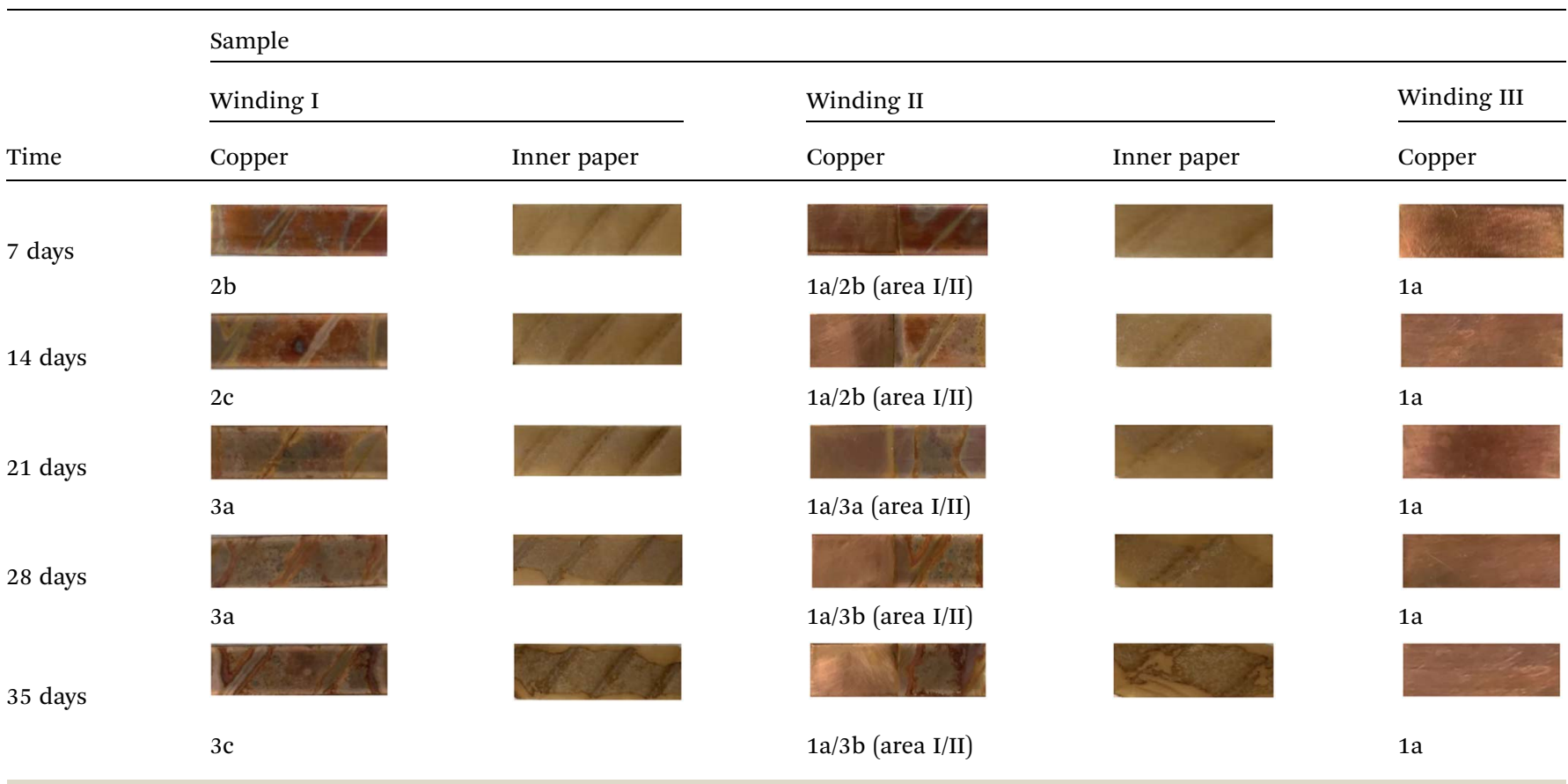

condition. For Winding I, more corrosive deposits were observed on the windings in acid-containing oil than in the original oil without acids. As the amount of acids increased in the insulating oil, the corrosion degree of the windings was intensified. Moreover, the corrosion degree of the copper strip in Winding I increased with the acid-containing oil, with formic acids showing the highest corrosion degree on the copper strip, followed by the combination of oleic and formic acids and oleic acids alone. The corrosion degree of the inner insulating paper in Winding I also increased with the acid-containing oil; however, the highest corrosion degree of paper was observed with oleic acids, followed by the combination of oleic and formic acids and formic acids alone. For Winding II, corrosive deposits were also deposited on area II of the copper strips and inner insulating papers, and the surface morphologies of area II were similar to the results for Winding I. However, regardless of the acid content, no deposit was found on area I of the copper strips. For Winding III, no deposit was observed on the copper strips. The bare copper

Table 6 Surface morphologies of the three types of windings, including copper strip and inner insulating paper under air condition

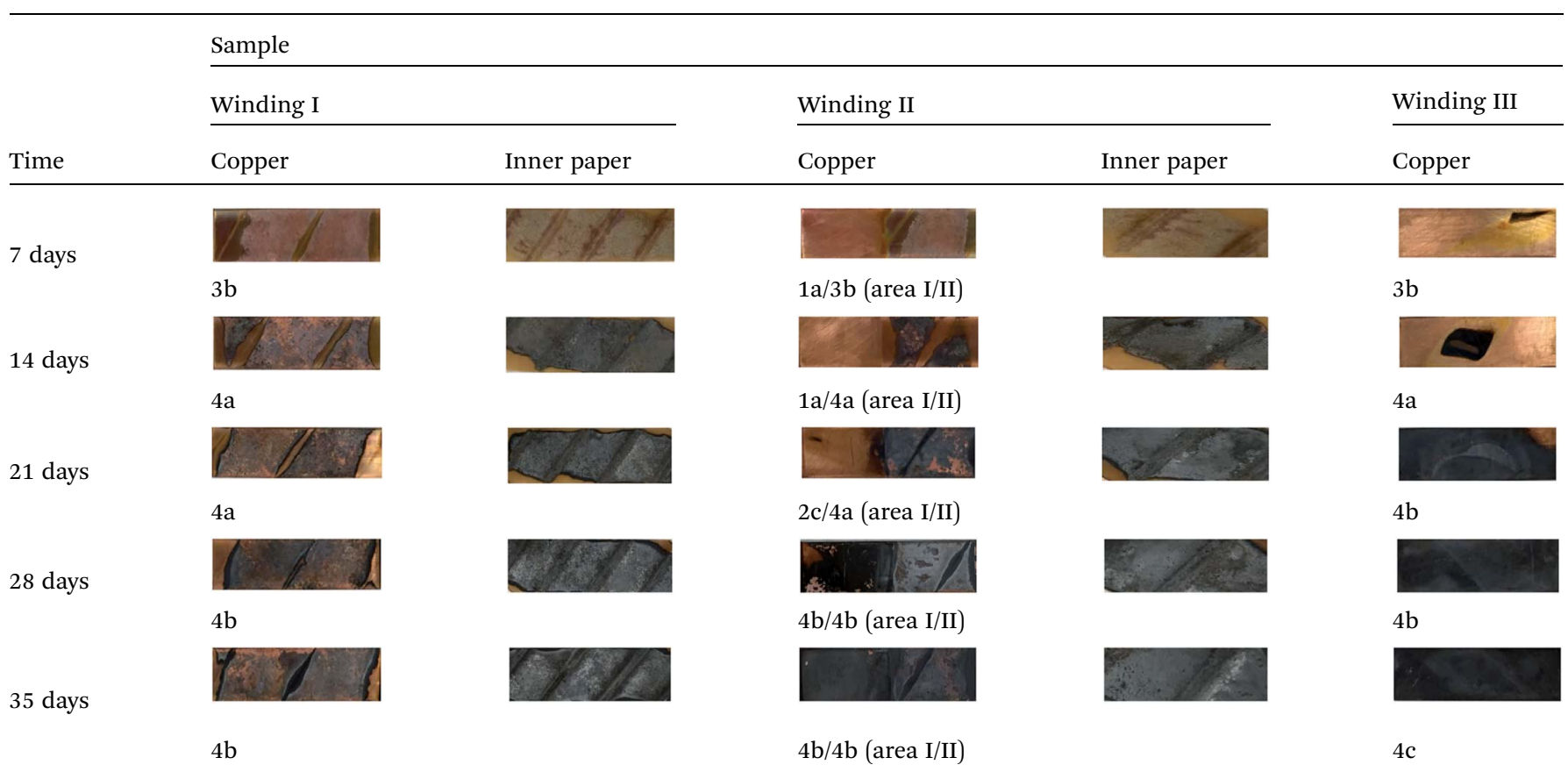


Table 7 Surface morphologies of the three types of windings, including copper strip and inner insulating paper, after the acid experiment

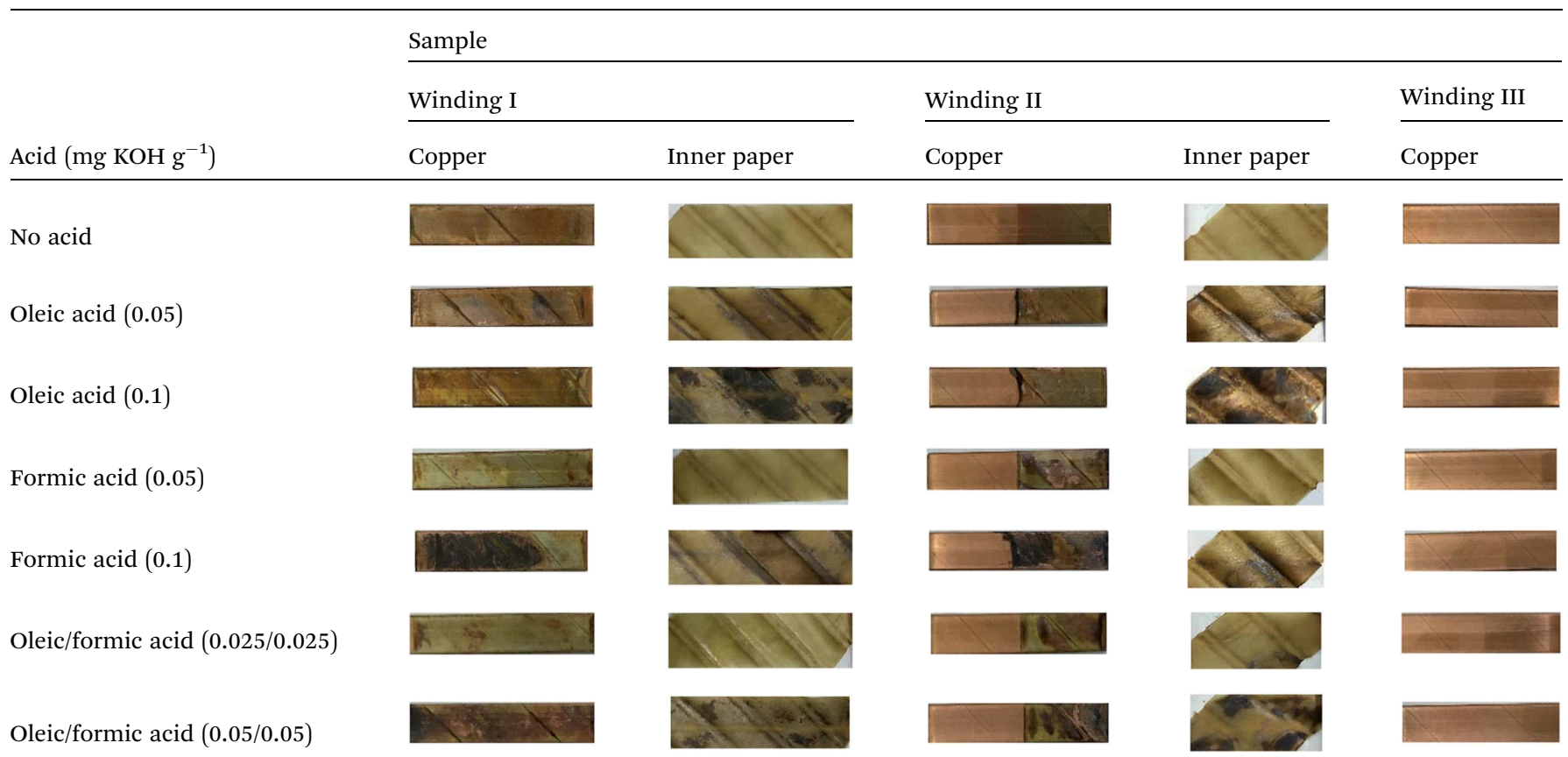

strip could not be corroded with acid-containing corrosive oil. Consequently, acids accelerated the formation of corrosive deposits on paper-wrapped copper strips.

\subsection{Microscopic morphology and composition element analysis of insulation windings}

SEM equipped with EDX was used to observe microscopic morphology and analyze the composition elements on the surface of insulation windings. Fig. 4 displays the SEM images and EDX maps of the copper strips under three different aging conditions. For Winding I, some corrosive particles on the copper strips were observed at day 21 of aging under nitrogen condition. Large areas of corrosive particles with different shapes and sizes were deposited on the copper strip of Winding I at day 21 of aging under air condition. More corrosive particles were observed for Winding I immersed in oil containing formic acids. According to the EDX maps of the copper strip, the atomic percentage of oxygen and sulfur on the copper strip under air condition was higher than that under nitrogen condition. This result indicated that copper sulfide and oxides increased and that oxygen accelerated the corrosion, which led to a large amount of corrosive deposits on the insulation windings.

Carbon, oxygen, copper, and sulfur were detected by EDX on the surface of corroded insulation windings. Fig. 5 shows the atomic percentages of sulfur and copper on Winding I under nitrogen and air conditions, respectively. As shown in Fig. 5(a), sulfur and copper contents were measured on the inner insulating paper under air and nitrogen conditions, respectively. Under nitrogen and air conditions, the atomic percentage ratio of copper and sulfur on insulating paper reached 2 and more than 2 , respectively. These results indicated that some amounts of copper sulfide were deposited on insulation windings after the reaction of DBDS and copper. ${ }^{8}$ Under air condition, insulation windings presented significantly higher sulfur and copper contents than those under nitrogen condition. This result indicated that copper sulfide deposition on insulation windings increased due to the presence of oxygen, which accelerated the corrosion degree of insulation windings.

Fig. 6 shows the atomic percentages of sulfur and copper on area II of Winding II under nitrogen and air conditions, respectively. As depicted in Fig. 6(a), sulfur and copper contents on the inner insulating paper under air condition were considerably higher than that under nitrogen condition. This finding was similar to the results for Winding I. As shown in Fig. 6(b), sulfur content on area I of the copper strip was extremely low under nitrogen condition, indicating that no copper sulfide formed under such condition. However, under air condition, sulfur content on area I of the copper strip increased rapidly at the late phase of aging, indicating that oxygen accelerated corrosion.

Fig. 7 shows the atomic percentages of sulfur on the copper strip for Winding III under nitrogen and air conditions. Results demonstrated extremely low sulfur content on the copper strip under nitrogen condition and high sulfur content on the copper strip under air condition. These findings indicated that under oxygen condition, the reaction of DBDS and copper can corrode bare copper strips. By contrast, bare copper strips were difficult to corrode under nitrogen condition.

\subsection{Physicochemical properties of insulating oil}

Fig. 8 shows the copper ions and oil acidity in different samples. For the three types of insulation windings, the concentration of 

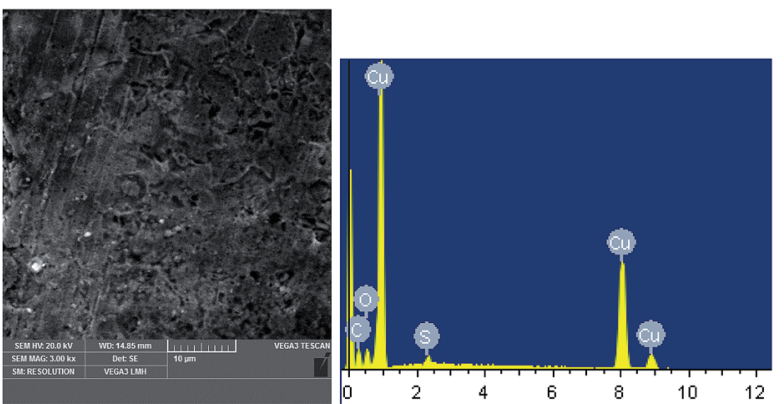

(a)
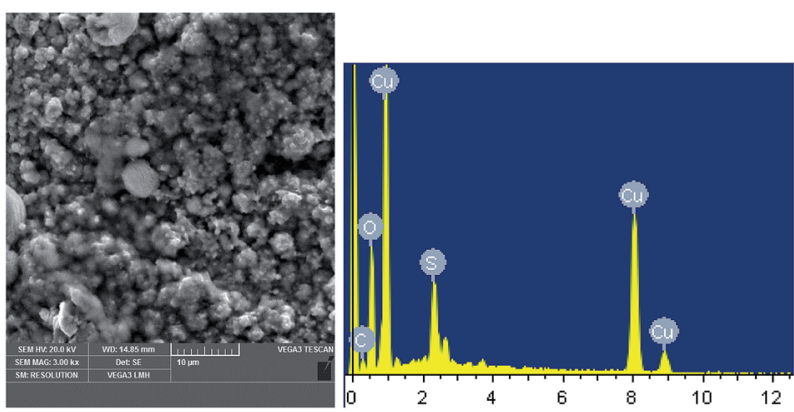

(b)
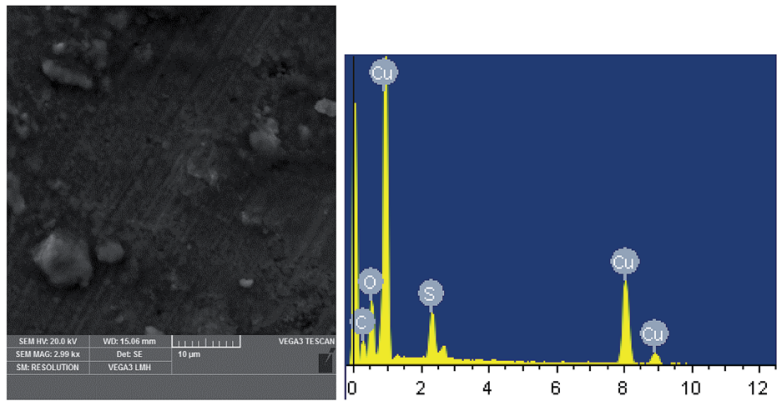

(c)

Fig. 4 SEM images and EDX maps of the copper strips under different aging conditions. (a) Winding $\mathrm{I}$ at day 21 of aging under nitrogen condition. (b) Winding I at day 21 of aging under air condition. (c) Winding I in oil containing formic acids $\left(0.05 \mathrm{mg} \mathrm{KOH} \mathrm{g}^{-1}\right)$.

copper ions and oil acidity were considerably higher under air condition than those under nitrogen atmosphere. More copper ions promoted oxidation and accelerated the aging of oil, thereby subsequently increasing conductivity and oil acidity. ${ }^{26}$ As shown in Fig. 8(a) and (b), for thermal aging under nitrogen condition, Winding I showed the least number of copper ions but exhibited the highest acidity. Winding III contained the highest number of copper ions but presented the lowest acidity. Winding I presented less copper ions but higher acidity than Windings II and III. Results agreed with those of the thermal aging under air condition. These findings indicated that the presence of insulating paper increased oil acidity and that oilpaper insulation was gradually oxidized and generated a series of oxidation products, including deleterious acidic substances and copper ions, thereby increasing the aging of insulating oil.

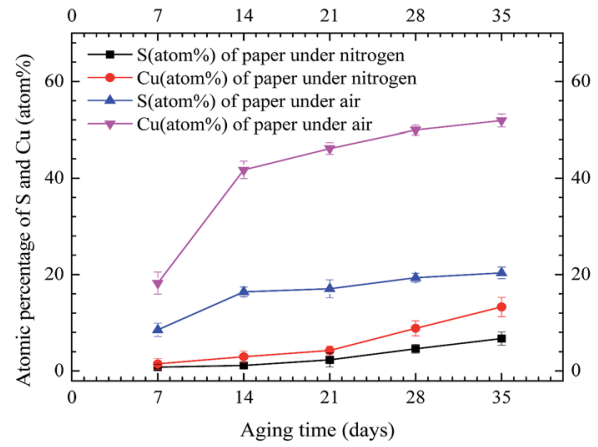

(a)

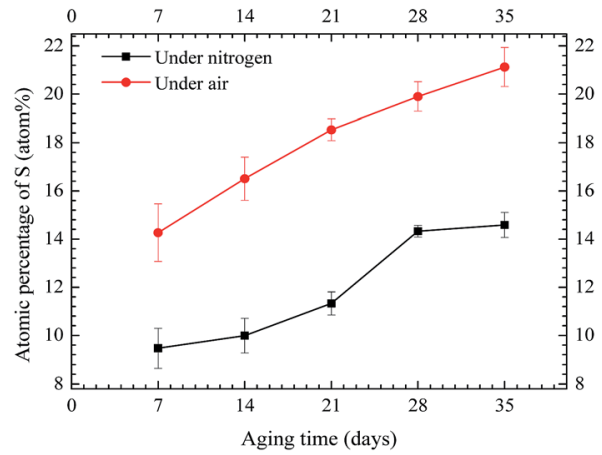

(b)

Fig. 5 EDX quantitation of sulfur and copper on Winding I under nitrogen and air conditions. (a) EDX results of inner paper. (b) EDX results of copper strip.

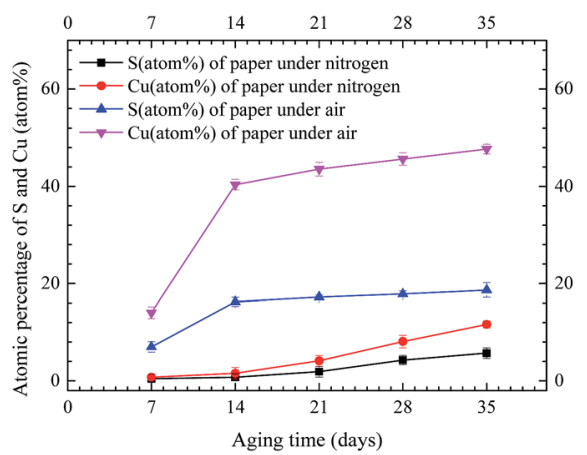

(a)

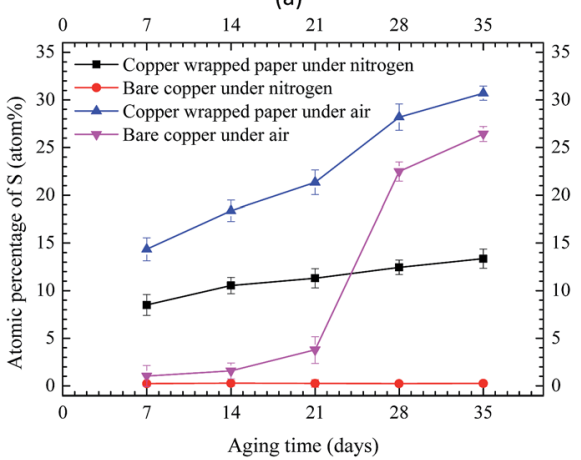

(b)

Fig. 6 EDX quantitation of sulfur and copper on Winding II under nitrogen and air conditions. (a) EDX results of inner paper. (b) EDX results of copper strip. 


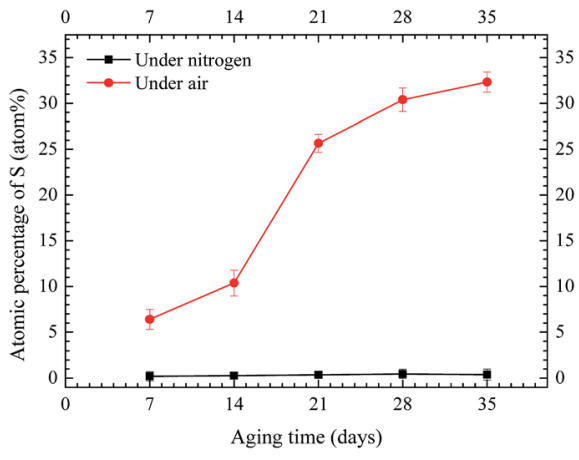

Fig. 7 EDX quantitation of sulfur on copper strip for Winding III under nitrogen and air conditions.

However, additional insulating paper decreased the dissolution of copper ions in oil, indicating that these materials prevented diffusion of copper ions in oil.

Fig. 9 shows the normalized amount of copper and sulfur deposited on the insulating paper and copper strip, respectively (area of copper strip was $20.08 \mathrm{~cm}^{2}$, area of paper was $20 \mathrm{~cm}^{2}$, half of the copper area was $10.04 \mathrm{~cm}^{2}$, and half of the paper area was $10 \mathrm{~cm}^{2}$ ). Fig. 10 shows the copper ions of the insulating oil for the three types of windings in the acid experiment. As shown in Fig. 9 and 10, higher amounts of copper were deposited on the insulating paper in oil with acids than those in oil without acids. The same trend was observed in the amounts of sulfur deposited on the copper strips and the concentrations of copper

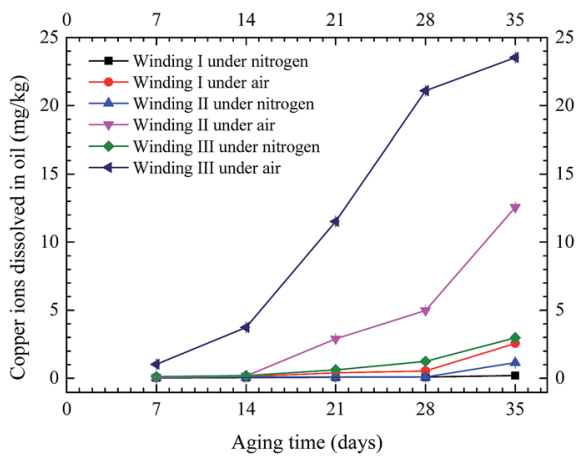

(a)

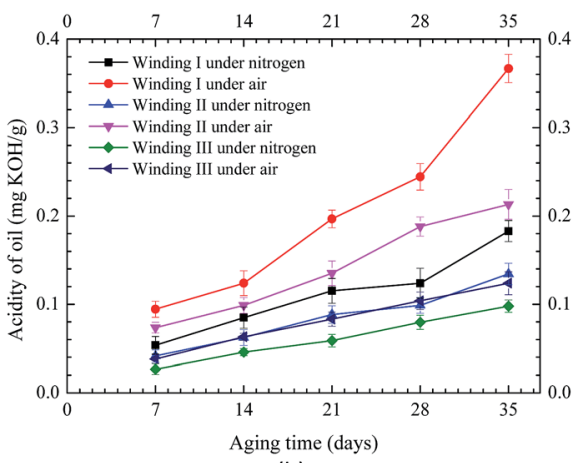

(b)

Fig. 8 Copper ions and acidity of insulating oil in different samples under nitrogen and air conditions. (a) Copper ions of oil. (b) Oil acidity.

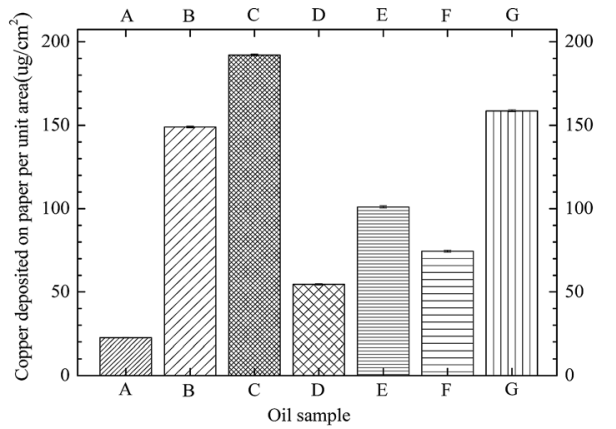

(a)

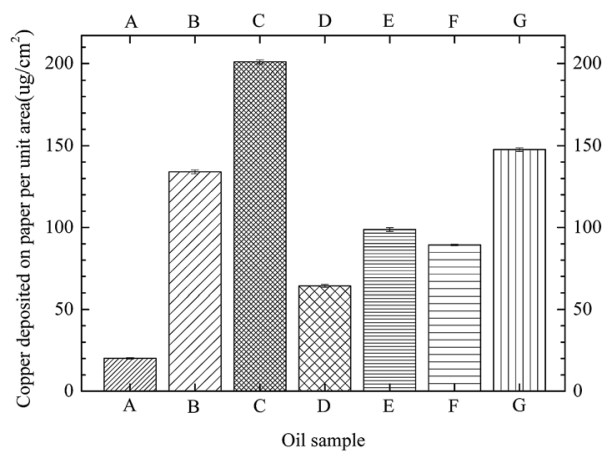

(b)

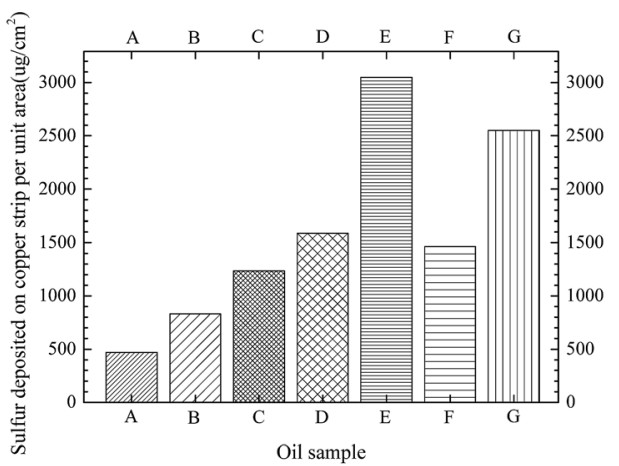

(c)

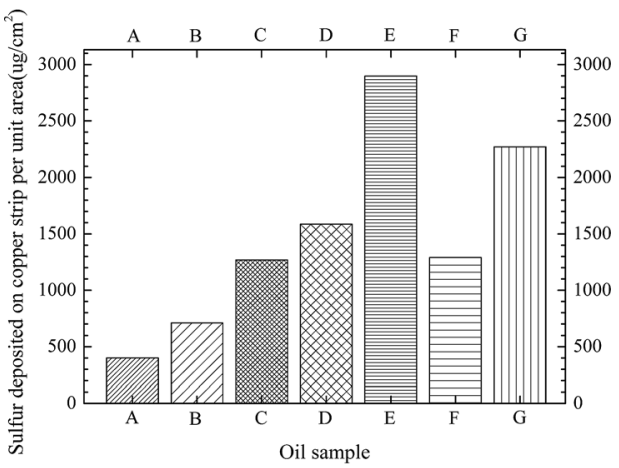

(d)

Fig. 9 Normalized amounts of copper and sulfur deposited on insulating paper and copper strip for different oil sample compositions (see Table 4). (a) Copper content of paper for Winding I. (b) Copper content of paper for area II of Winding II. (c) Sulfur content of copper strip for Winding I. (d) Sulfur content of copper strip for area II of Winding II. 


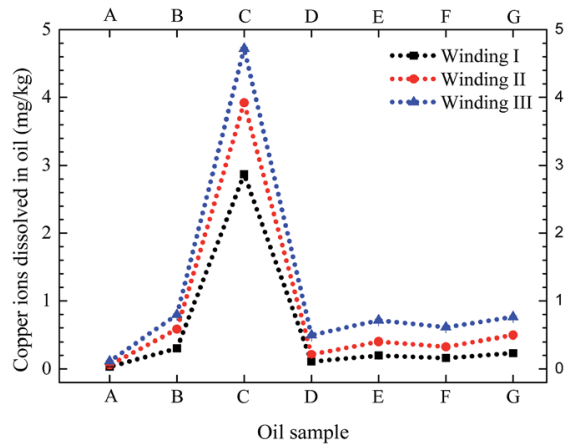

Fig. 10 Copper ion concentration in insulating oil containing different acidic additives (see Table 4) from three types of winding (see Table 3).

dissolved in oils. Generally, the total amount of copper sulfide in oil with acids was considerably higher than that in oil without acids, and the amount of copper sulfide formation increased with the increase of dissolution of acids in oil. In comparison of Winding I and area II of Winding II, the amount of copper deposited on the insulating paper per unit area showed the same trend, along with the amount of sulfur deposited on the copper strip per unit area. Moreover, the amount of copper deposited on paper and the concentration of copper ions in oil with formic acids were lower than those in oil with oleic acids. By contrast, the amount of sulfur deposited on the copper strips in oil with formic acids was higher than that in oil with oleic acids. For Winding III and area I of Winding II, no sulfur was deposited on the copper strips in oil with acids. These findings suggested that the bare copper strip could not be corroded with acid-containing oil and that copper sulfide easily dissolved in oleic acid, which simulated high molecular-weight acids compared with formic acid, which represented low molecularweight acids. Formic acid was more conducive to the copper sulfide formation on the copper strip than oleic acid.

Meanwhile, according to the results of Fig. 9, it can be seen that the amount of sulfur deposited on copper strip was much higher than the amount of copper deposited on paper. Copper and innermost layer paper were all corroded, but the copper as conductor can be directly react with DBDS to form $\mathrm{Cu}_{2} \mathrm{~S}$, then some of $\mathrm{Cu}_{2} \mathrm{~S}$ migrate to innermost layer paper, resulting in amount of $\mathrm{Cu}_{2} \mathrm{~S}$ deposited on the copper was certain higher than that on the paper. ${ }^{7,12}$

\section{Discussion and analysis}

According to the preliminarily experimental results, the existence of paper-wrapped resulted in a large amount of corrosive deposits on insulation windings, however, bare copper strip cannot be corroded under nitrogen condition even when under high DBDS concentration in insulating oil. Acidic substances and copper ions are the main reason.

Oil-paper insulation was gradually oxidized to generate the acidic substances, especially the degradation of insulating paper resulted in a large amount of low molecular-weight acids. It has been reported that DBDS partially decomposed into R-SH

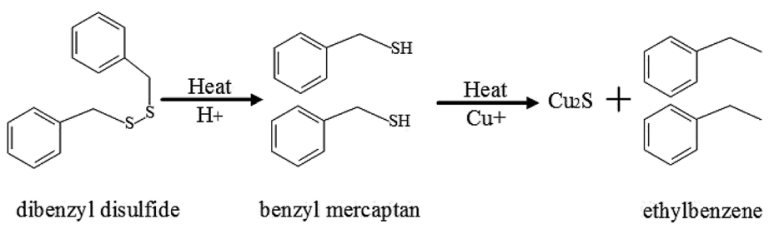

(a)

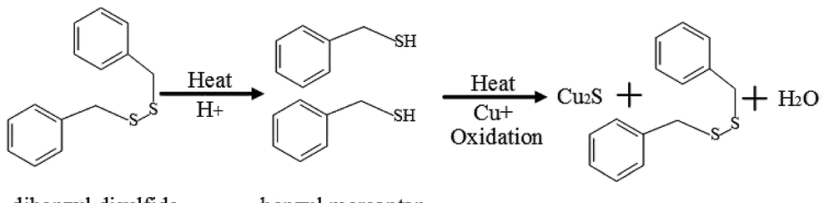

dibenzyl disulfide

(b)

Fig. 11 Reaction in the degradation of DBDS into benzyl mercaptan and its oxidation. (a) Degradation of DBDS into benzyl mercaptan. (b) Oxidation reaction of benzyl mercaptan.

and other single-ring products under high-temperature conditions and with the presence of acidic substances, ${ }^{25}$ as shown in Fig. 11(a). The corrosion activity of R-SH is stronger than that of DBDS, leading to the acceleration of sulfur corrosion. The degradation of organic sulfur compounds involved an oxidative attack that was localized at sulfur atoms, whereas R-SH molecules were oxidized, not only copper sulfide formation, but also some DBDS regeneration, as shown in Fig. 11(b). Acidic substances accelerated copper sulfide formation (Fig. 12).

Copper sulfide formation on insulation windings was expected to occur through the reaction of DBDS and copper ions. Copper was polarized positively, whereas sulfur was polarized negatively. Radicals in acid-containing oil can accelerate the bonding of copper and DBDS to promote corrosion, ${ }^{\mathbf{1 4}}$ leading to the acceleration of sulfur corrosion.

During the operation of oil-immersed transformer, both insulating paper and oil may inevitably connect with copper, so there are always some copper ions found in oil. It also should be noted that galvanic corrosion happened in oil-paper insulation. ${ }^{23}$ For paper-wrapped copper, paper wrapped copper lead to low oxygen concentrations between paper and copper, forming anode, and cathode was formed on the bare copper. Anodic processes (oxidation action) resulted in the acceleration of copper ions, as expressed in the following formulas:

Anode:

$$
\mathrm{Cu}-\mathrm{ne}^{-} \rightarrow \mathrm{Cu}^{n+}
$$

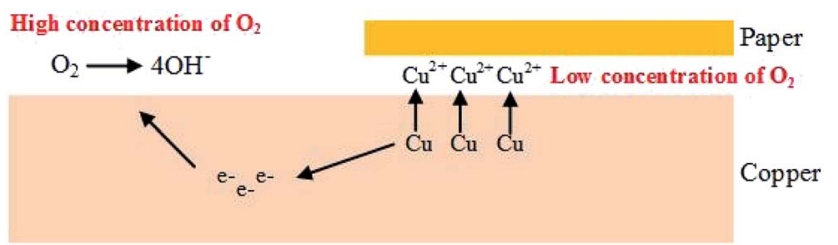

Fig. 12 Oxygen concentrations cell induced by the existence of paper-wrapped copper. 


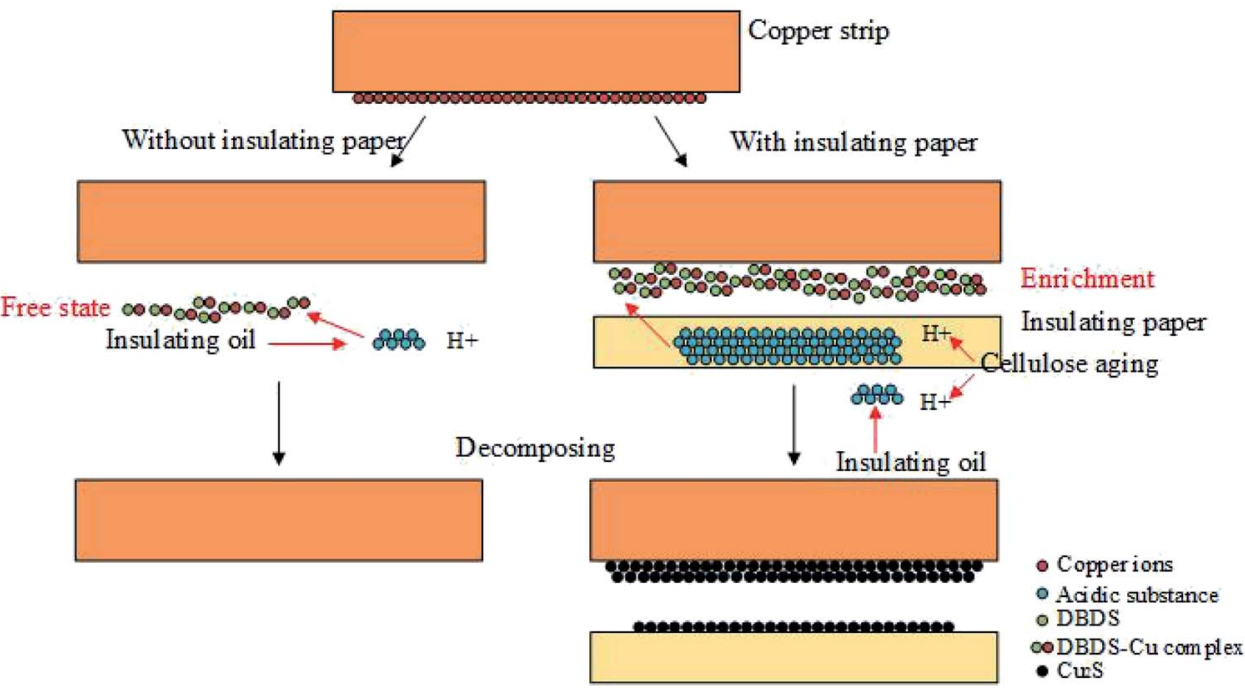

Fig. 13 Schematic mechanism for the local enrichment of copper ions and acids between copper conductor and paper for the acceleration of copper sulfide formation.

Cathode:

$$
\mathrm{O}_{2}+2 \mathrm{H}_{2} \mathrm{O}+4 \mathrm{e}^{-} \rightarrow 4 \mathrm{OH}^{-}
$$

where, $\mathrm{e}-$ is the electron, and $\mathrm{n}$ is the valence of the cations.

In general, the existence of paper-wrapped accelerated copper ions adsorption, which reacted with DBDS to generate copper sulfide, and the removal of paper eliminated the diffusion barrier of copper ions, the diffusion of copper ions may significantly affected sulfur corrosion. ${ }^{23}$ An increase in acidity also promoted the release of copper ions, leading to the acceleration of sulfur corrosion and oil-paper aged. And the oxidation oil are significantly influenced by copper release, which resulted in hydrogen peroxide decomposition and free radical formation, this process would promote the oxidation process of the insulation oil. ${ }^{23}$

$$
\begin{aligned}
& \mathrm{ROOH}+\mathrm{Cu}^{+} \rightarrow \mathrm{RO}^{\cdot}+\mathrm{Cu}^{2+}+\mathrm{OH}^{-} \\
& \mathrm{ROOH}+\mathrm{Cu}^{2+} \rightarrow \mathrm{ROO}+\mathrm{Cu}^{+}+\mathrm{H}^{+}
\end{aligned}
$$

where $\mathrm{R}$ represents the alkyl group.

Moreover, copper release kinetics could also be influenced by oxidation of oil-paper in turn, and oxygen concentration contributed to a surge in copper ions, this phenomenon accelerated corrosion and resulted in corrosion of bare copper strips. $^{23}$

Due to the strong adsorption of paper, some polar molecules, including copper ions and acidic substances, can be adsorbed, ${ }^{19}$ especially the innermost insulating paper that directly contact with copper, thereby increasing the concentration of $\mathrm{H}^{+}$and $\mathrm{Cu}^{2+}$ region between the copper conductor and insulating paper. Thus, local enrichment of acids and copper ions in copper-insulating paper can promote sulfur corrosion, which served as an important precondition of sulfur corrosion (Fig. 13).

\section{Conclusion}

Based on collected experimental data and corrosion theory, the present study proposes a corrosion mechanism for local enrichment of copper ions and acids in copper-insulating paper contact leading to the acceleration of copper sulfide formation. The amount of formed copper sulfide can be increased by the presence of insulating paper, and acids promote copper sulfide formation on insulation windings. Increase in oxygen also contributes to a surge in copper ion dissolution in oil. This dissolution can accelerate corrosion and result in the corrosion of insulation windings. Thus, monitoring and controlling the oxygen content of transformer oil are remarkably instructive and helpful for operations. As caused by strong adsorption ability of insulating paper, degradation of oilpaper insulation results in increased amounts of acids and copper ions adsorbed by insulating paper. Increase in acids and copper ions increases the concentrations of $\mathrm{H}^{+}$and copper ion areas between the copper conductor and insulating paper. These conditions can significantly promote corrosion. Moreover, the local enrichment of acids and copper ions in copper-insulating paper is an important precondition in copper sulfide corrosion.

\section{Conflicts of interest}

There are no conflicts to declare.

\section{Acknowledgements}

The authors would like to acknowledge the National Science Foundation of China (51277187) and Fund Project of State Grid Corporation of China, Jiangsu (J2017034).

\section{References}

1 R. J. Liao, L. J. Yang and J. Li, IEEE Trans. Dielectr. Electr. Insul., 2011, 18, 303-311. 
2 T. K. Saha and P. Purkait, IEEE Trans. Dielectr. Electr. Insul., 2008, 15, 568-582.

3 F. Scatiggio, V. Tumiatti, R. Maina, M. Tumiatti, M. Pompili and R. Bartnikas, IEEE Trans. Power Delivery, 2008, 23, 508509.

4 CIGRE WG A2-32, Final Report No. 378, 2009.

5 R. Maina, V. Tumiatti, F. Scatiggio, M. Pompili and R. Bartnikas, IEEE Trans. Power Delivery, 2011, 26, 23912393.

6 R. M. De Carlo, M. C. Bruzzoniti, C. Sarzanini, R. Maina and V. Tumiatti, IEEE Electrical Insulation Magazine, 2013, 20, 557-565.

7 S. Toyama, J. Tanimura, N. Yamada, E. Nagao and T. Amimoto, IEEE Trans. Dielectr. Electr. Insul., 2009, 16, 509-515.

8 M. Facciotti, P. S. Amaro, A. F. Holt, R. C. Brown, P. L. Lewin, J. A. Pilgrim and P. N. Jarman, Corros. Sci., 2014, 84, 172-179.

9 J. Hajek, M. Dahlund, L. Patterson and G. Bennstam, $A B B$ Review, 2004, 3, 61-63.

10 F. Kato, T. Amimoto, E. Nagao, N. Hosokawa and J. Tanimura, IEEE Trans. Dielectr. Electr. Insul., 2011, 18, 1869-1876.

11 T. Amimoto, N. Hosokawa, E. Nagao, J. Tanimura and S. Toyama, IEEE Trans. Dielectr. Electr. Insul., 2009, 16, 1489-1495.

12 S. Toyama, K. Mizuno, F. Kato, E. Nagao, T. Amimoto and N. Hosokawa, IEEE Trans. Dielectr. Electr. Insul., 2011, 18, 1877-1885.

13 S. Ren, L. Zhong, Q. Yu, X. Cao and S. Li, IEEE Trans. Dielectr. Electr. Insul., 2012, 19, 849-854.

14 H. Kawarai, Y. Fujita, J. Tanimura, S. Toyama, N. Yamada, E. Nagao and T. Amimoto, IEEE Trans. Dielectr. Electr. Insul., 2009, 16, 1430-1435.
15 V. Tumiatti, C. Roggero, M. Tumiatti, S. D. Carlo, R. Maina and S. Kapila, IEEE Trans. Dielectr. Electr. Insul., 2012, 19, 1633-1641.

16 J. Wada, G. Ueta and S. Okabe, IEEE Trans. Dielectr. Electr. Insul., 2013, 20, 307-316.

17 T. Amimoto, E. Nagao, J. Tanimura, S. Toyama and N. Yamada, IEEE Trans. Dielectr. Electr. Insul., 2009, 16, 257-264.

18 P. Wiklund, M. Levin and B. Pahlavanpour, IEEE Electrical Insulation Magazine, 2007, 23, 6-14.

19 CIGRE WG A2-40, Final Report No. 625, 2015.

20 DIN 51353, 1985.

21 ASTM D 1275, 2006.

22 IEC 62535, 2008.

23 O. Sevastyanova, B. Pasalskiy and B. Zhmud, Engineering, 2015, 7, 514-529.

24 T. K. Saha, IEEE Trans. Dielectr. Electr. Insul., 2003, 10, 903917.

25 L. Lewand and S. Reed, 75th Annual International Doble Client Conference, 2008, 1-20.

26 L. J. Liao, C. Tang and L. J. Yang, IET Electric Power Applications, 2009, 3, 407-412.

27 IEC62021, 2003.

28 L. E. Lundgaard, W. Hansen, D. Linhjell and T. P. Terence, IEEE Trans. Power Delivery, 2004, 1, 230-238.

29 L. E. Lundgaard, W. Hansen, S. Ingebrigtsen, D. Linhjell and M. Dahlund, IEEE Int. Conf. Dielectr. Liq., 15th, 2005, 381384.

30 L. E. Lundgaard, W. Hansen and S. Ingebrigtsen, IEEE Trans. Dielectr. Electr. Insul., 2008, 2, 540-546.

31 ASTM D 130, 2012. 